\title{
A Structural Configuration with Separate Substructures towards Reducing the Seismic Damage of Spatial Structures with Rectangular Plan
}

\author{
Dabin Yang $\mathbb{D}^{1},{ }^{1,2}$ Litai Sun, ${ }^{1}$ Hao Wang $\mathbb{D},{ }^{1}$ Lei Liu, ${ }^{1}$ Mingjin Li, ${ }^{1}$ and Xiangyi Sun ${ }^{1}$ \\ ${ }^{1}$ School of Civil Engineering, Shandong Jianzhu University, Jinan 250101, China \\ ${ }^{2}$ Key Laboratory of Building Structural Retrofitting and Underground Space Engineering (Shandong Jianzhu University), \\ Ministry of Education, Beijing, China
}

Correspondence should be addressed to Hao Wang; wanghao19@sdjzu.edu.cn

Received 8 July 2020; Revised 23 September 2020; Accepted 30 September 2020; Published 13 October 2020

Academic Editor: Sonia E. Ruiz

Copyright (C) 2020 Dabin Yang et al. This is an open access article distributed under the Creative Commons Attribution License, which permits unrestricted use, distribution, and reproduction in any medium, provided the original work is properly cited.

Seismic damage of spatial structures of rectangular plan with RC substructures was observed in several earthquakes, especially in the RC substructures. In order to reduce the seismic damage potential, a new structural configuration of spatial structure of rectangular plan is proposed, the substructures of which are composed of the steel substructure and the RC substructure. The latter only bears the vertical load of roof by the arrangement of horizontal sliding bearings between the roof and the RC substructure. The pushover analyses are performed on a steel braced frame and an RC frame with similar lateral stiffness, and the results show that the lateral capacity of the steel structure is much larger than those of the RC structures. A spatial structure of rectangular plan with two different substructures is designed according to Chinese structural designing codes. Seismic time history analyses are carried out for the spatial structure under five ground motions. The results show that the damage mainly concentrates on the substructures, and the seismic performance of the structure with steel and RC substructures is much better than that of the structure with RC substructures.

\section{Introduction}

Spatial structures have been widely used in gymnasia, public halls, auditorium, and stadiums. In most cases, a typical spatial structure consists of two parts: upper roof and substructure, and the roof is usually in the structural form of steel spatial structures including flat spatial truss or latticed shell, while the latter tends to be the reinforced concrete (RC) structures. The seismic performance of roofs will be greatly influenced by substructures [1-3]. Although it has been proven by many earthquakes that the seismic damage of spatial structures is relatively light compared with the multistory structures, the damages are reported in several earthquakes [4-9], especially in the structural part around roof bearings and $\mathrm{RC}$ substructures.

In the Hanshin-Awaji Earthquake in 1995 in Japan, the structural damage to spatial structures was mainly observed in the RC substructures, while damage to steel roof structures was comparatively minor [4]. The damage of an RC column in a school gymnasium with rectangular plan is shown in Figure 1 [4].

In 2011, Tohoku earthquake with the magnitude of 9.0 hit Japan. Even more severe damages to spatial structures than ever before were observed. Other than the roof damage, the roof bearings and $\mathrm{RC}$ substructures supporting steel roofs were extensively damaged according to the Joint Editorial Committee for the Report on the Great East Japan Earthquake Disaster [9], some of which are shown in Figure 2. In the earthquake, the spherical latticed domes including their substructures were seldom damaged, and most of the damaged spatial structures were in the form of rectangular plan, regardless of the roof type of cylindrical latticed shells, flat spatial trusses, and chevron moment frames. 


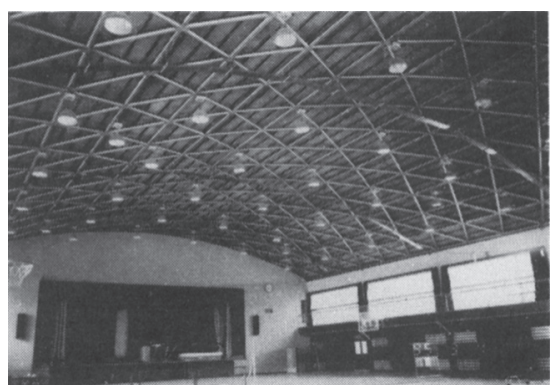

(a)

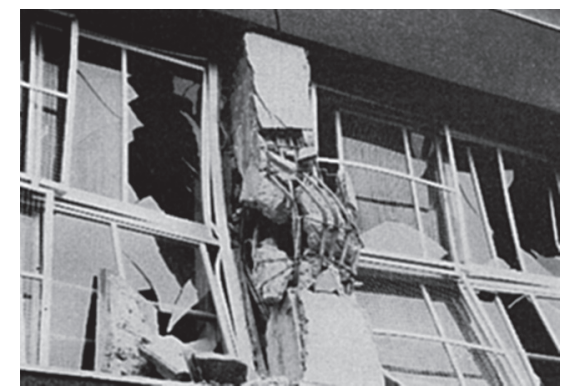

(b)

FIGURE 1: Damage of an RC column of a school gymnasium in Hanshin-Awaji earthquake. (a) Interior view of the high school gym. (b) Damage of a column in the gym.

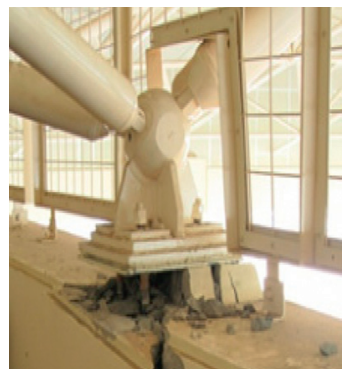

(a)

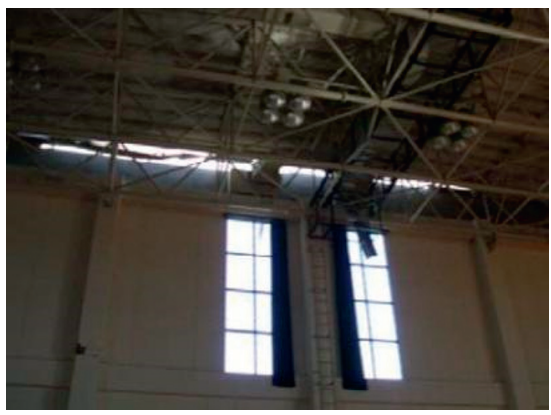

(d)

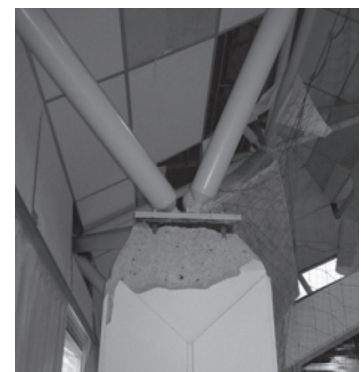

(b)

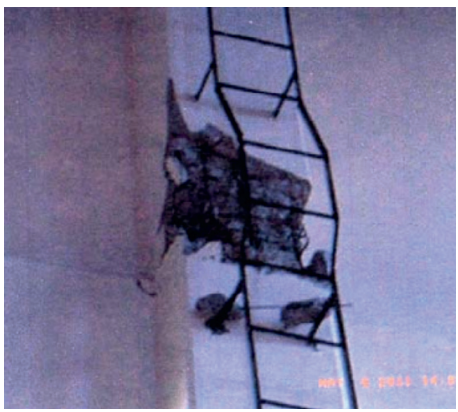

(e)

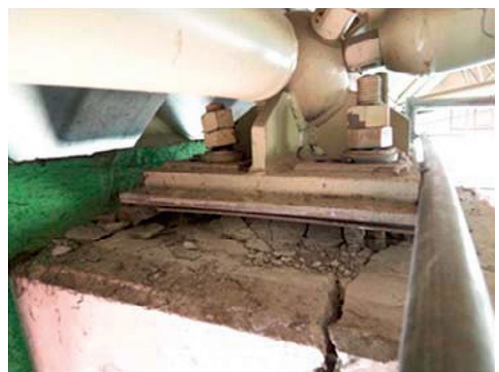

(c)

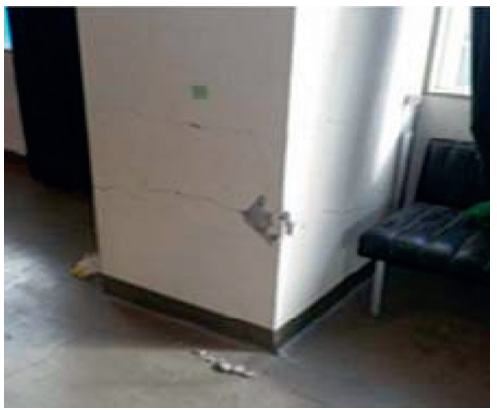

(f)

FIgURE 2: Damage of bearings and RC columns of spatial structures in Tohoku earthquake. (a) Bearing-1, (b) bearing-2, (c) bearing-3, (d) column middle-1, (e) column bottom-2, and (f) column bottom-1.

Most of spatial structures tend to be used as shelters for refugees in the event of earthquake, so their seismic performance level should be enhanced compared with ordinary structures, and it is expected to be immediately used without any need of repair after earthquakes. As mentioned above, most of the substructures of spatial structures are RC structures due to the lesser cost of RC compared with steel, but it is well known that the seismic performance of steel structures is much better than that of RC structures. In order to reduce the seismic damage potential, a new structural configuration of spatial structures with rectangular plan is proposed, the substructures of which are composed of two parts: the steel substructure bearing the horizontal and vertical loads of roof and the RC substructure only bearing the vertical load of roof. The seismic performances are studied by static pushover analyses and seismic time history analyses under different ground motions.

\section{Structural Configuration and FE Models}

2.1. Basic Principle of Structural Configuration. Generally speaking, the RC structure has a relatively high capacity on compression but a low capacity on bending. The basic principle of the structural configuration is to divide the substructures into two separate parts, the steel substructure and the RC substructure, in which the former bears the horizontal and vertical loads of the roof, and the latter only bears the vertical load of the roof by the arrangement of horizontal sliding connections of the RC substructure and the roof. Therefore, the horizontal seismic forces of the roof can only be transferred to the steel substructure rather than the RC substructure by this kind of configuration, so the shear force and the bending moment of the RC substructure can be significantly reduced. However, the steel substructure should be strong enough to retain necessary strength and 
stiffness due to the horizontal seismic forces, so highstrength steel cables are used as the diagonal braces. The seismic performance of single-layer latticed domes with separate substructures in accordance with this structural configuration principle is proven to be excellent [10], but the seismic performance of the spatial structure with the rectangular plan has not been studied. Furthermore, it is different and more complicated than the dome-shaped spatial structure in terms of structural configuration.

2.2. FE Models. SAP2000 V19 is used for FE models. A spatial structure with the rectangular plan of $64 \mathrm{~m} \times 48 \mathrm{~m}$ and the substructure height of $9 \mathrm{~m}$ is taken as the structural model. As to the roof, a single-layer latticed shell with the height of $9.6 \mathrm{~m}$ is selected as the structural form, and the geometrical modeling procedure in sequence is shown in Figure 3. In the first step shown in Figure 3(a), the plan is meshed into $16 \times 12$ squares with the side length of $4 \mathrm{~m}$, and the coordinate origin, point $\mathrm{O}$, is taken as the central point of the plan, and points $\mathrm{A} \sim \mathrm{D}$ are the middle points of each side, respectively. Lines OA and OD are in the positive directions of $x$-axis and $y$-axis, respectively. Then point $\mathrm{T}$ is determined by elevating point $\mathrm{O}$ by $9.6 \mathrm{~m}$ along the positive direction of $z$-axis, and the circular arcs ATB and CTD are drawn in the second step. Seven arcs in vertical plans passing through the 14 points along the longer side of the plan and the arc AT are depicted, as is shown in Figure 3(c). Vertical lines are drawn from the square points till the intersections with the eight arcs in the former step; thus all the intersections and the corresponding points in the plan sides are connected to form $1 / 4$ part of the latticed shell in the 5th step. Finally, the whole latticed shell is created by mirroring the $1 / 4$ part of the latticed shell, as shown in Figure 3(e).

For the structure with steel and RC substructures, the RC substructures are connected with the roof shell by horizontal sliding bearings, so the horizontal boundary constraint stiffness for the shell will only be provided by steel substructure. In order to maintain the necessary horizontal boundary constraint stiffness of the latticed shell, a boundary beam structure in the plan $A B C D$ shown in Figure 4 is implemented in the structure.

Two kinds of substructures are considered: steel and RC substructures shown in Figure 5 and RC substructures shown in Figure 6, and the bird views and two side views of the whole structure with steel and RC substructures are depicted in Figure 7. All the column intervals are $8 \mathrm{~m}$ and both steel and RC beams are in the height of $8 \mathrm{~m}$ for both cases. For the case of steel and RC substructures, the same steel substructures distribute in the four corners, comprising steel columns with fixed bottoms, steel beams with flexible connections with the columns, and tension-only concentrical braces, and all the steel column tops are pin-connected with the roof members. All the RC column bottoms are fixed on the ground. Equal constraints in SAP2000 shown in Figure 8 are used for modeling the horizontal sliding bearings: the vertical DOFs (degrees of freedom) of column tops are constrained with corresponding roof joints in the same locations, and the other five DOFs of the two joints remain independent; thus, the horizontal sliding effects can be simulated.

The masses and gravity of members are automatically considered by SAP2000. Super dead load of $0.5 \mathrm{kN} / \mathrm{m}^{2}$ and live load of $0.5 \mathrm{kN} / \mathrm{m}^{2}$ for the latticed shell are considered in the design to determine member sections, and the super dead load is converted to nodal masses during the seismic time history analyses. All the member sections are determined according to Chinese structural designing codes [11-14]. The stress-strain relation of the tension-only steel brace of high-strength cable is shown in Figure 9 [15], of which Young's modulus, yield stress, and ultimate stress are $1.9 \times 10^{5} \mathrm{MPa}, 1764 \mathrm{MPa}$, and $1960 \mathrm{MPa}$, respectively [16]. All the other steel members are of the steel grade Q345 with Young's modulus of $2.05 \times 10^{5} \mathrm{MPa}$ and yield stress of $345 \mathrm{MPa}$. As shown in Figure 10, all the roof members and boundary beams are of rectangular pipe sections, of which the weaker axes are the roof surface normals. The member sections of the steel substructure are shown in Table 1. The concrete grade for all the RC structures is the widely used C40 in China, with the design value of axial compressive strength being 19.1 MPa. The member sections and reinforcement configurations of the RC substructure are shown in Figure 11, and the reinforcements of RC column and corner column are listed in Table 2, where three levels of reinforcements, R0, R1, and R2, are presented, all of which can meet the designing requirements of Chinese structural designing codes above, and $\rho$, the ratio of longitudinal reinforcement of R2 level for RC column, is a little larger than the maximum limit, 5\%, prescribed in the Chinese code for design of concrete structures [11]. In the structural FE models, the shorter side of each RC column is parallel to the axial line of the RC beam connected.

\subsection{Dominant Vibration Modes. SS-SRC and SS-RC are used} to label the structure with steel and RC substructures and the structure with RC substructures below.

For both of the two structures with different substructures, as shown in Figure 12, the vibration shapes of the first two modes are the horizontal vibration in $y$-direction and $x$ direction, respectively, whose modal participating mass ratios $M_{x}, M_{y}$, and $M_{z}$ in the three directions are listed in Table 3. It is obvious that the first two vibration modes are the dominant modes for seismic responses, since the modal participating mass ratios are relatively large, especially for the structure with RC substructures. It is worth noting that the RC substructures in the SS-SRC structure remain stationary in the first two vibration modes, as shown in Figures 12(a) and 12(b), which results in less modal participating mass ratios than those of SS-RC structure. The periods of the first two modes are close for the two structures, which suggests that the lateral stiffnesses are almost the same.

2.4. Static Pushover Analyses. To illustrate the comparison of steel substructure and RC substructure, static pushover analyses are performed on two structures shown in Figure 13. The steel structures are composed of steel column 


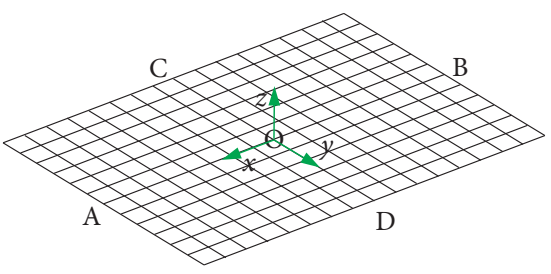

(a)

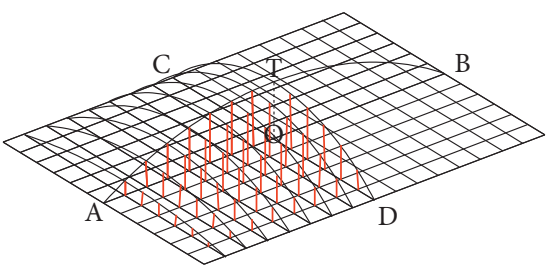

(d)

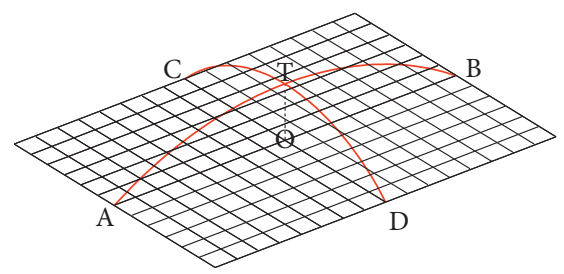

(b)

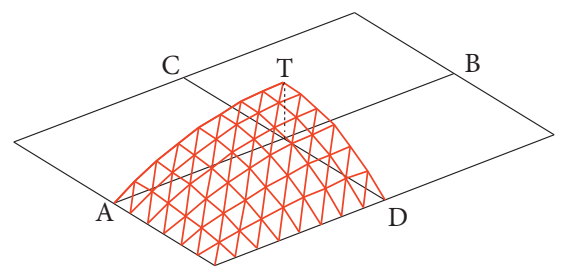

(e)

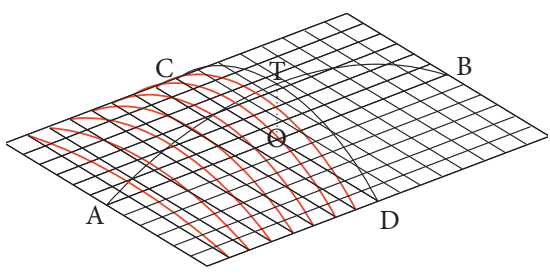

(c)

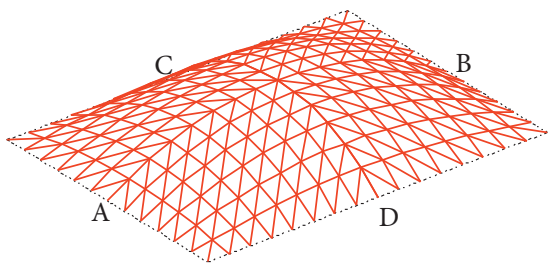

(f)

Figure 3: Geometrical modeling procedure of roof. (a) 1st step, (b) 2nd step, (c) 3rd step, (d) 4th step, (e) 5th step, and (e) 6th step.

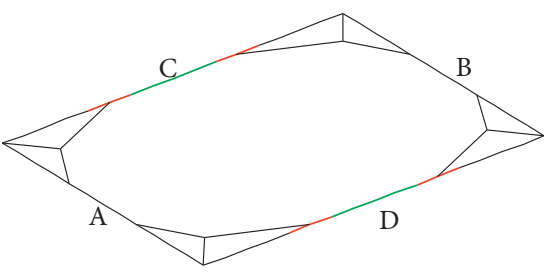

FiguRE 4: Boundary beam structure of the latticed shell.

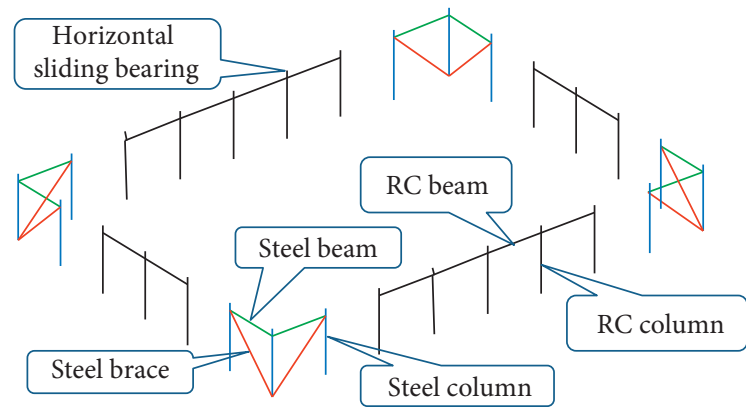

FIGURE 5: Steel and RC substructures.

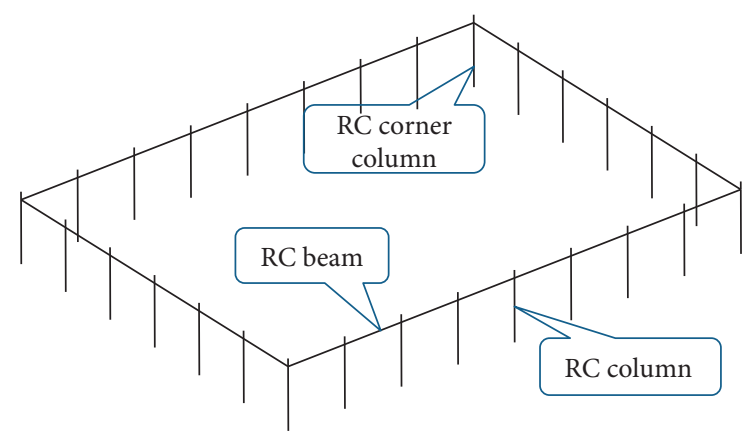

FIgURE 6: RC substructures.

with fixed bottoms, steel beam with flexible connections with the columns, and tension-only concentrical brace, and all the sections and materials are the same as shown in Table 1 .
Similarly, the RC columns and beams in the pushover models have the same sections and materials presented in Figures 11(a) and 11(c) and Table 2, and the numbers of RC columns and beams are determined according to the lateral stiffness of the steel structure; that is, the lateral stiffnesses of the steel structure and the RC structure are almost same. According to the Chinese code for design of concrete structures [11], the axial compression ratio of RC column, $R_{a c}$, is defined as

$$
R_{a c}=\frac{N}{f_{c} A_{c}},
$$

where $N$ and $f_{c}$ are the compression force and the design value of axial compressive strength of the RC column. Three different compression forces are calculated according to equation (1) when $R_{a c}$ is $0,0.2$, and 0.4 , respectively, and then they are applied on the column tops of the two kinds of structures.

The plasticity is usually considered by plastic hinges in SAP2000. As shown in Figure 14, the force-deformation behavior of a plastic hinge is defined by five points labeled $\mathrm{A}$, $\mathrm{B}, \mathrm{C}, \mathrm{D}$, and $\mathrm{E}$, which denote the origin, yielding, ultimate capacity, residual strength, and total failure. Three additional deformation measures at points IO (immediate occupancy), LS (life safety), and CP (collapse prevention) are also presented in SAP2000 for different automatic hinges. Different performance levels are represented by different colors in postprocess, as shown in Figure 14. All the automatic hinge properties of different sections and load conditions implemented in SAP2000 V19 are described in ASCE 41-13 [17]. In the pushover analyses, the PMM hinge defined in ASCE 41-13 [17] is designated on the two ends of the steel columns and RC columns, and M hinge defined in ASCE 41-13 [17] is designated on the two ends of the RC beam. The hinge of steel braces is also defined according to ASCE 41-13 [17] based on the nonlinear relations in Figure 9.

The relations of lateral forces and lateral displacements on the column tops are depicted in Figure 15. It can be seen that the elastic capacity of the steel structure is much larger than those of the RC structures, irrespective of the 


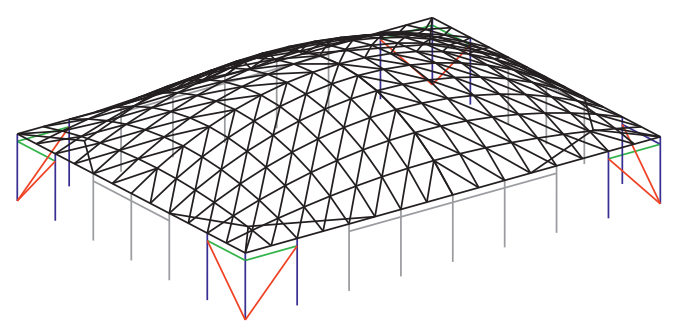

(a)

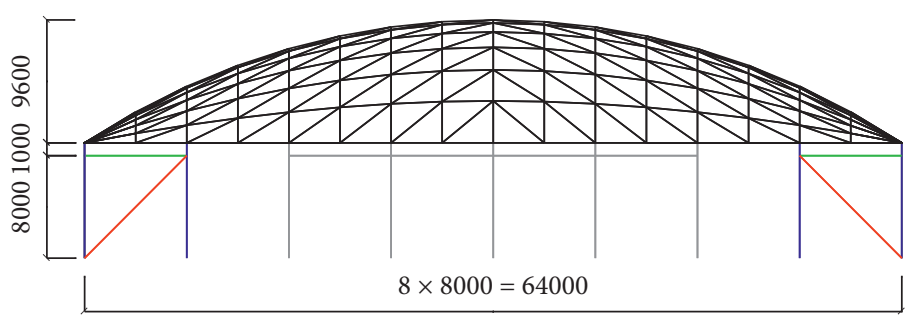

(b)

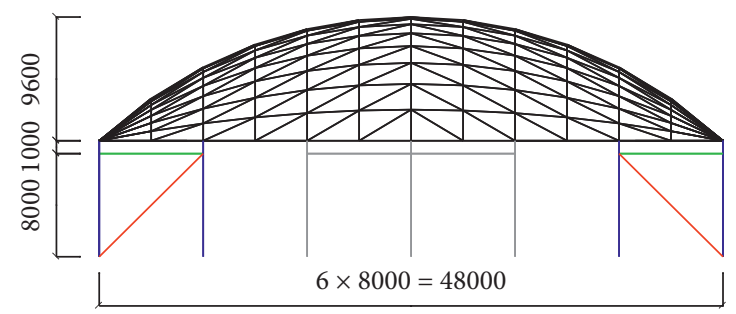

(c)

Figure 7: Whole structure with steel and RC substructures. (a) Bird view, (b) side view-1, and (c) side view-2.

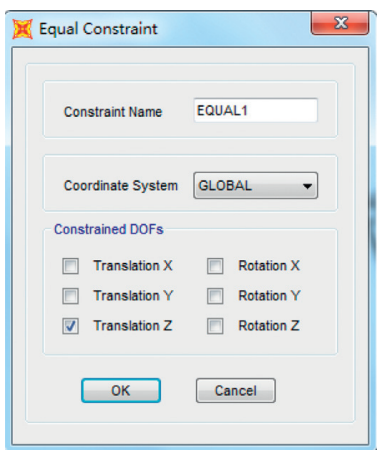

FIGURE 8: Equal constraints for modeling the horizontal sliding bearings.

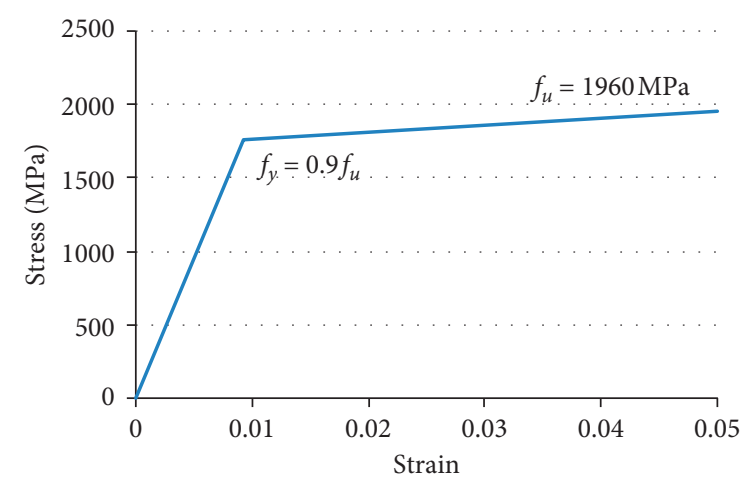

Figure 9: Stress-strain relation of steel braces under tension.

reinforcements of the columns. The calculation results show that the transfer points from elastic to plastic in the pushover curves of steel structure correspond to the yielding point of steel braces; that is, the high elastic capacity of steel structure is mainly creditable to the high strength of steel braces. For RC structures, more reinforcements in the columns will increase the lateral force capacity, which basically decreases with the increase of the vertical loads applied.
2.5. Seismic Analyses. Seismic time history analyses under different ground motions are performed to compare the seismic performances of the two kinds of structures. Because the R1 reinforcement is the most commonly used reinforcement level in structural design practice, only the R1 reinforcement is used for the RC columns of both structures in the comparison. Other than the hinges mentioned above, the automatic PMM hinges are designated on the two ends and middle points of the roof including the beam ring members. By assuming damping ratio as 0.035 [14] due to the structure including steel and RC, Rayleigh damping with two coefficients calculated by the periods of the first two vibration modes is used. The Hilber-Hughes-Taylor method with alpha as zero is used in the analyses, in which $P$-delta and large displacements effects are considered.

2.6. Ground Motions. As shown in Table 4, five ground motions in three directions are selected as the input seismic accelerations, in which the first one is one of the ground motions in the Tohoku earthquake recorded in Fukushima, the prefecture where many spatial structures with RC substructures were damaged by seismic ground motions in the earthquake according to the Joint Editorial Committee for the Report on the Great East Japan Earthquake Disaster [9]. All the accelerations in the three directions are not scaled, and the maximum horizontal PGA (peak ground acceleration) of the acceleration is 1069 gal, which is inputted in $y$-direction shown in Figure 3(a). Zhai and Xie [18] recommended the most unfavorable real seismic design ground motions for rock, stiff soil, medium soil, and soft soil site conditions in terms of three typical period ranges of structures, and one of the five ground motions in each group for the middle-period $(0.5-1.5 \mathrm{~s})$ structures is selected as the next four ground motions listed in Table 4, which are expected to result in severe damage for the structure with dominant vibration modal periods from $0.5 \mathrm{~s}$ to $1.5 \mathrm{~s}$ on rock, stiff soil, medium soil, and soft soil site conditions. 

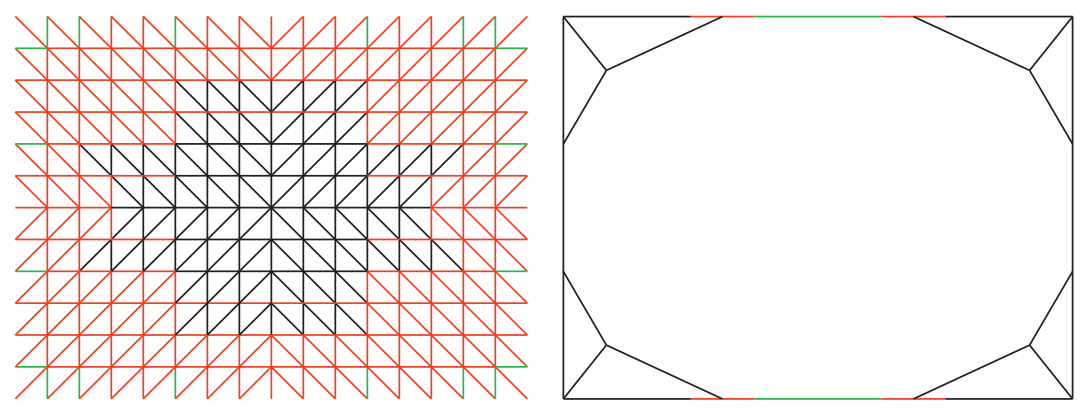

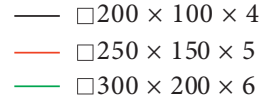

(a)

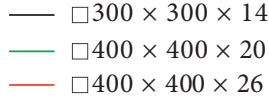

(b)

FIGURE 10: Member sections of the latticed shell. (a) Roof members; (b) boundary beam structure.

TABLE 1: Steel member sections and yield stresses.

\begin{tabular}{lccc}
\hline Member & Section $(\mathrm{mm})$ & Steel grade & Yield stress $(\mathrm{MPa})$ \\
\hline Steel column & $\square 400 \times 400 \times 16$ & Q345 & 345 \\
Steel beam & $\mathrm{H} 400 \times 200 \times 8 \times 13$ & Q345 & 345 \\
Steel brace & $\varnothing 50$ & 1960 & 1764 \\
\hline
\end{tabular}

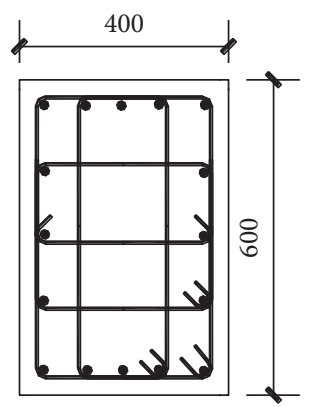

(a)

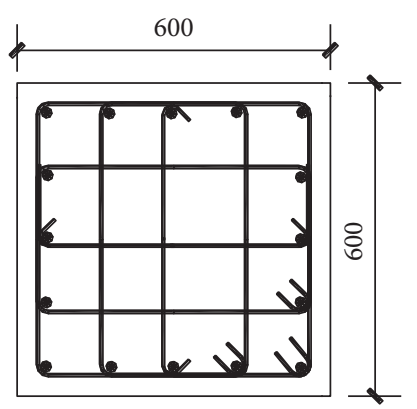

(b)

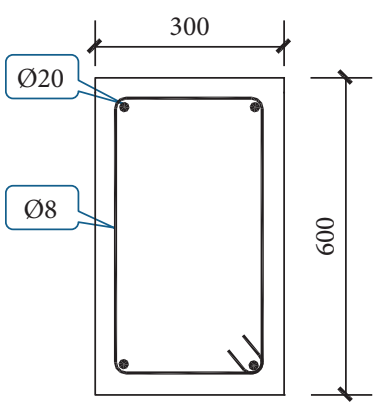

(c)

FIgURE 11: RC member sections and reinforcement configurations. (a) RC column, (b) RC corner column, and (c) RC beam.

TABLE 2: Reinforcements of RC column and RC corner column.

\begin{tabular}{lccccc}
\hline Level & Longitudinal reinforcement $(\mathrm{mm})$ & Transverse reinforcement $(\mathrm{mm})$ & $\rho$ of RC column $(\%)$ & Steel grade & Yield stress $(\mathrm{MPa})$ \\
\hline R0 & $\varnothing 18$ & $\varnothing 8 @ 100$ & 1.7 & HRB400 & 400 \\
R1 & $\varnothing 25$ & $\varnothing 12 @ 100$ & 3.3 & HRB400 & 400 \\
R2 & $\varnothing 32$ & $\emptyset 14 @ 100$ & 5.4 & HRB400 & 400 \\
\hline
\end{tabular}

${ }^{*} \rho=A_{s} / A_{c}$, where $A_{s}$ and $A_{c}$ are the areas of longitudinal reinforcement and column section, respectively.

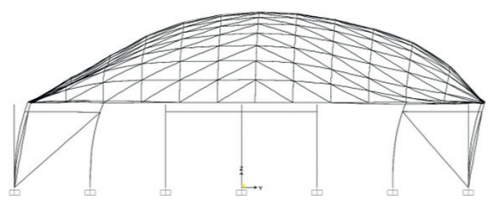

(a)

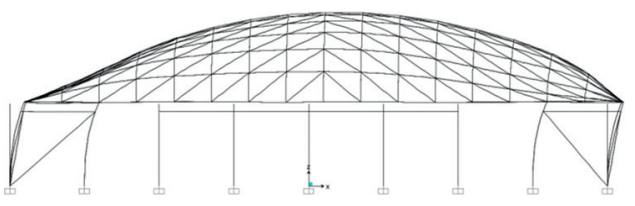

(b)

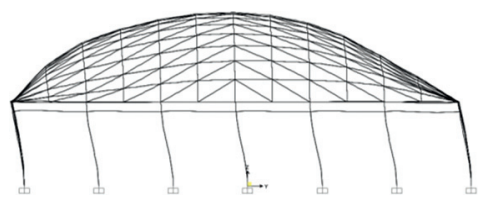

(c)

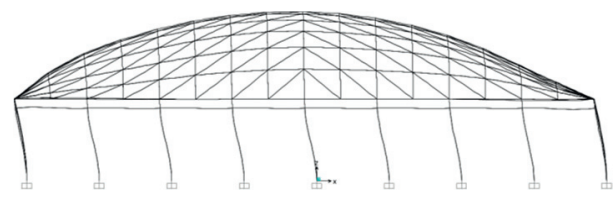

(d)

Figure 12: The first two vibration modes. (a) 1st mode of SS-SRC; (b) 2nd mode of SS-SRC; (c) 1st mode of SS-RC; (d) 2nd mode of SS-RC. 
TABle 3: The first two modal participating mass ratios.

\begin{tabular}{lccccc}
\hline Structure & Mode & Period (s) & $M_{x}$ & $M_{y}$ & $M_{z}$ \\
\hline \multirow{2}{*}{ SS-SRC } & 1 & 0.591 & 0 & 0.75 & 0 \\
& 2 & 0.572 & 0.77 & 0 \\
\multirow{2}{*}{ SS-RC } & 1 & 0.612 & 0 & 0.96 & 0 \\
& 2 & 0.585 & 0.98 & 0 \\
\hline
\end{tabular}

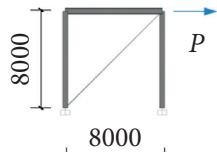

(a)

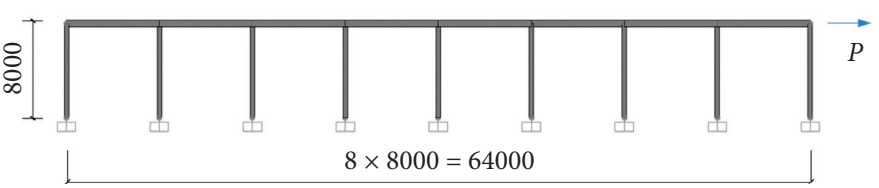

(b)

Figure 13: Pushover models. (a) Steel structure; (b) RC structure.

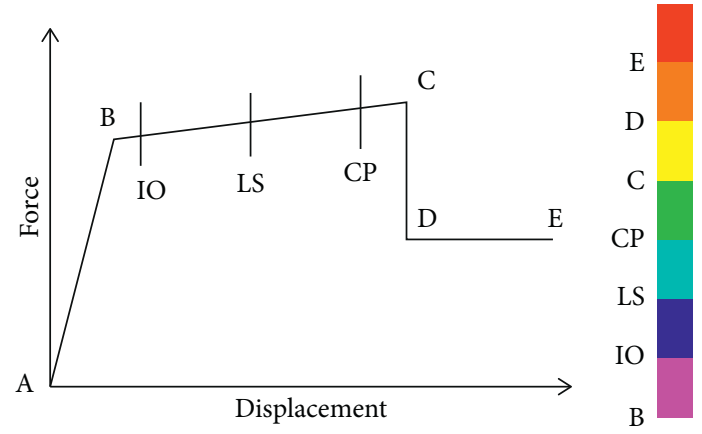

FIgURE 14: Force-deformation behavior of hinge.

Each group of accelerations of three directions is scaled in the same ratio, and the larger PGA of the two horizontal accelerations for each ground motion is scaled to 700 gal and inputted in $y$-direction. The pseudoacceleration response spectrums of all the scaled accelerations in $y$-direction are shown in Figure 16. It can be seen that, from $0 \mathrm{~s}$ to $0.6 \mathrm{~s}$, the period range of the spatial structures, Kobe's ground motion is the largest, so the structures are expected to be damaged most severely under Kobe's ground motion among all the five ground motions.

\section{Results}

All the roof members including the boundary beam structure and all the steel braces remain elastic under all the ground motions. The maximum axial stresses of the latticed shell members and the maximum resultant displacements of the latticed shells are illustrated in Figures 17 and 18. It can be seen that both the maximum axial stresses of the latticed shell members in SS-RC and SS-SRC structures are lower than the yielding strength. The maximum resultant displacements of the latticed shells in SS-RC and SS-SRC structures are close, except in the case of Kobe earthquake, where the displacement of SS-RC is much larger than that of SS-SRC, and this large discrepancy will be explained below.

The final plastic hinges of different levels under all the ground motions for substructures are shown in Figure 17. It is clear that the damage of the SS-RC structures is much larger than that of the SS-SRC structures. For the SS-RC structures, hinges with the state after $\mathrm{E}$ occur under all the ground motions except the Mammoth Lakes ground motion, while the hinges remain in state $\mathrm{B}-\mathrm{IO}$ under all the ground motions except Kobe's ground motion for the SS-SRC structures. Therefore, except Kobe's ground motion, the SS-SRC structures can be used as refugee shelters without any repair, while the SS-RC structures need to be retrofitted on many members because the hinges beyond state IO occur under all the ground motions. As mentioned before, the most severe damage occurs under Kobe's ground motion: other than several hinges with the state after E, all the column bottoms of the SS-RC structure reach the hinge state C-D, that is, beyond the ultimate capacity, while for the SS-SRC structure, all the hinges in the $\mathrm{RC}$ columns remain in state $\mathrm{B}-\mathrm{IO}$ except two IOLS hinges, and two IO-LS hinges appear in the steel columns.

The maximum resultant lateral displacements of the RC column tops in the two kinds of structures are depicted in Figure 19, from which the lateral displacements of the RC column tops in the RC structures are larger than those of the SRC structures, the comparative relation of which is the same as that of plastic hinge states shown in Figure 20. In the SS-RC structures, all the horizontal seismic forces and displacements due to the roof weight will be transferred to the RC columns, while those forces and displacements will only be transferred to the steel substructures in SS-SRC structures, and the RC substructures only bear the horizontal forces and displacements due to self-weight and parts of the 


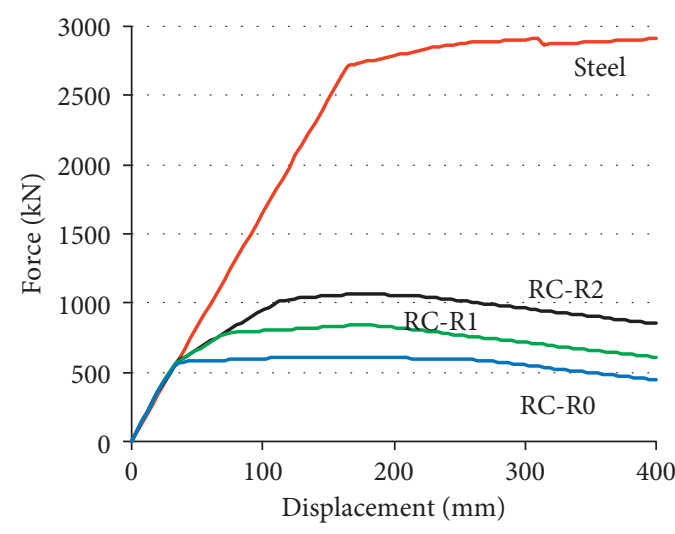

(a)

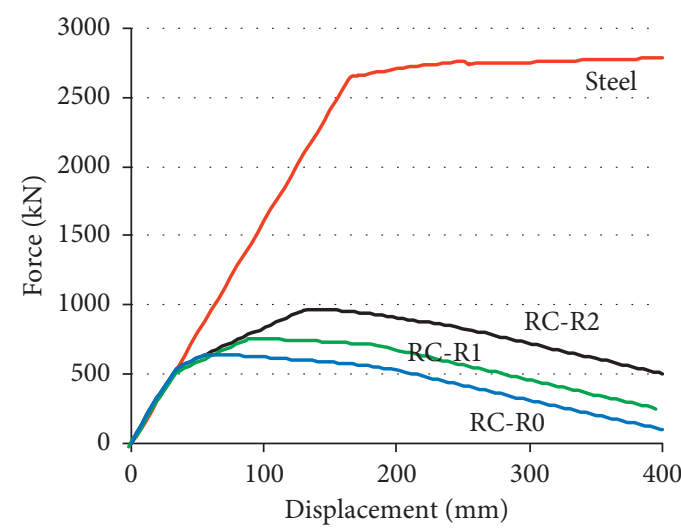

(b)

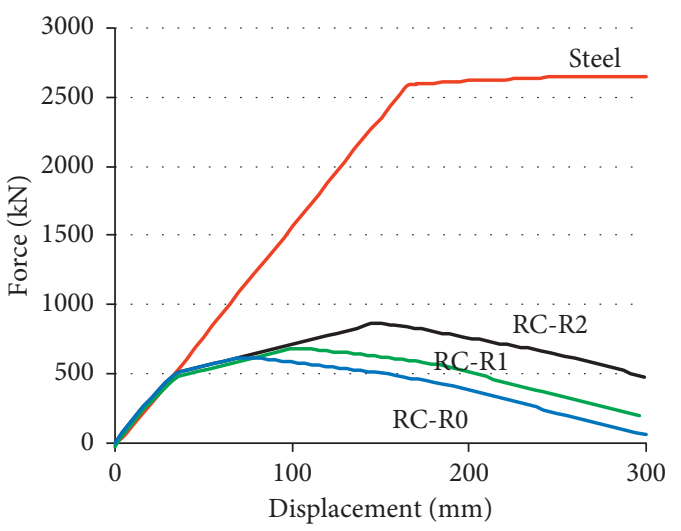

(c)

FIGURE 15: Force displacement of pushover analyses under different axial compression ratio of RC column $R_{a c}$. (a) $R_{a c}=0$, (b) $R_{a c}=0.2$, and (c) $R_{a c}=0.4$

TABLE 4: Ground motions.

\begin{tabular}{lcccc}
\hline Earthquake & Year & Station & Magnitude & PGA $_{y}($ gal $)$ \\
\hline Tohoku & 2011 & FKS018 & 9.0 & 1069 \\
Mammoth Lakes & 1980 & CSMIP 54214 & 6.2 & 700 \\
Chi-Chi & 1999 & TCU136 & 7.6 & 700 \\
El Centro & 1940 & USGS 0117 & 6.9 & 700 \\
Kobe & 1995 & CUE & 6.9 & 700 \\
\hline
\end{tabular}

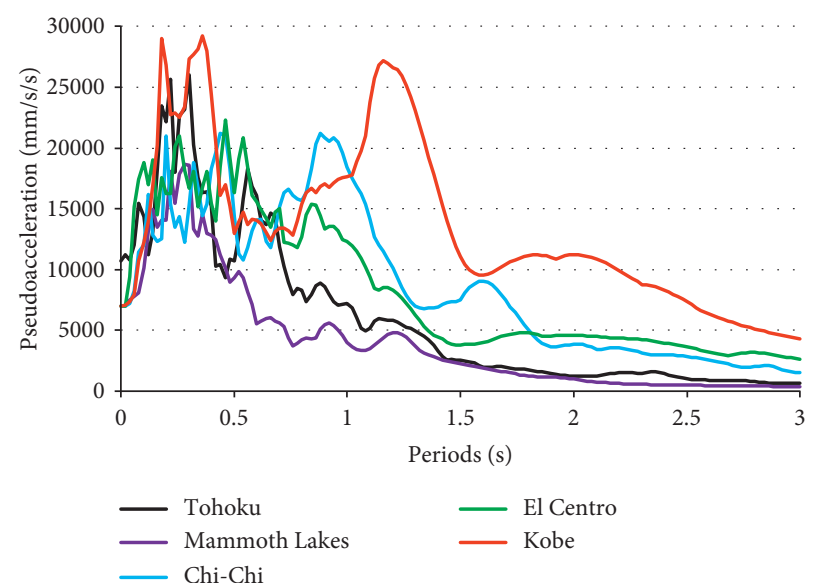

Figure 16: Pseudoacceleration response spectrums. 


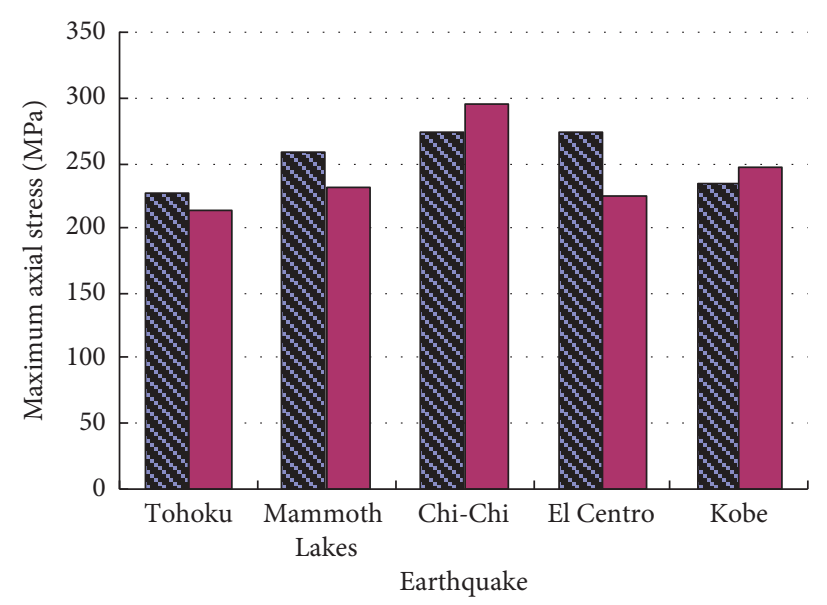

SS-RC

$\square$ SS-SRC

FIgURE 17: Maximum axial stresses of the latticed shell members.

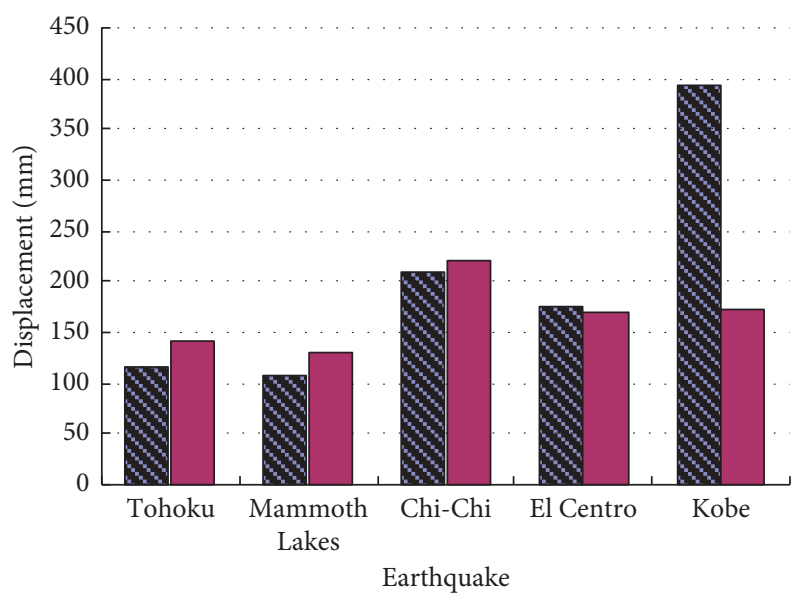

aSS-RC

$\square$ SS-SRC

FIGURE 18: Maximum resultant displacements of the latticed shells.

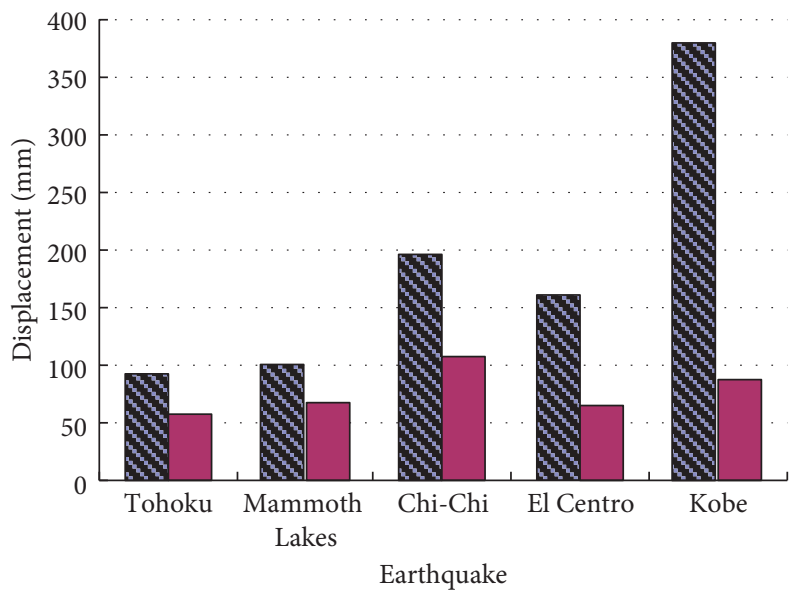

SS-RC

SS-SRC

FIGURE 19: Maximum resultant lateral displacements of the RC column tops. 


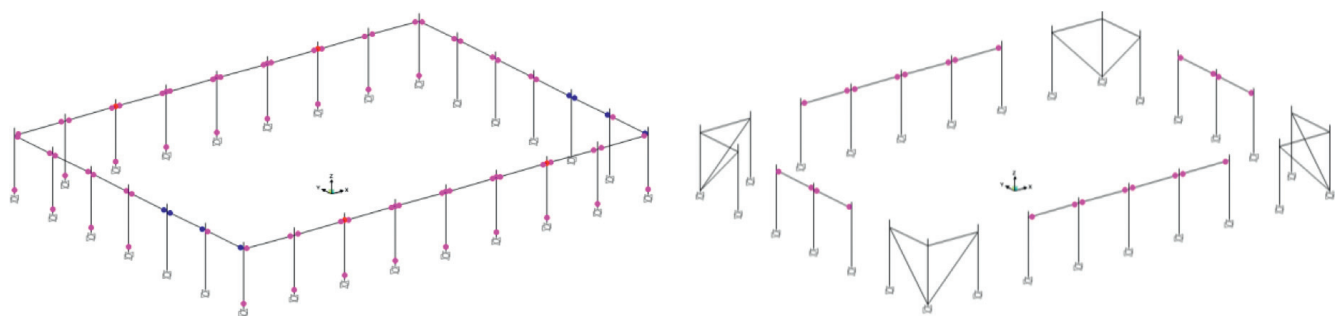

(a)

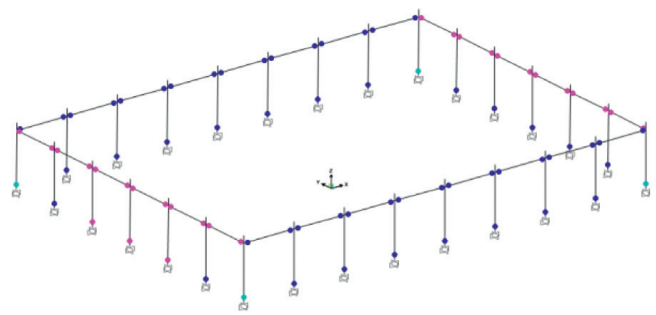

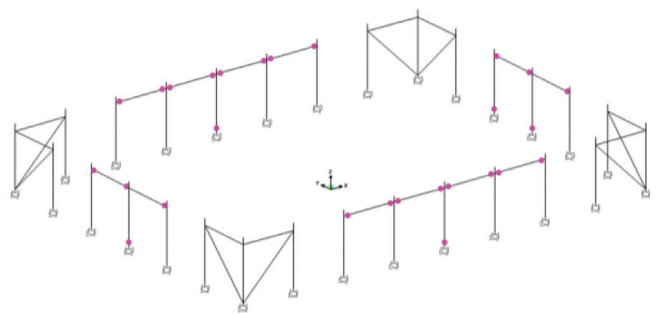

(b)

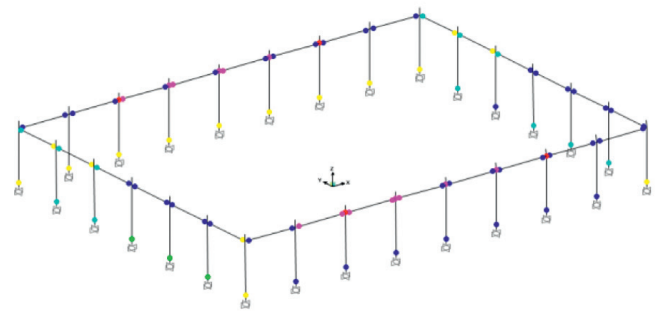

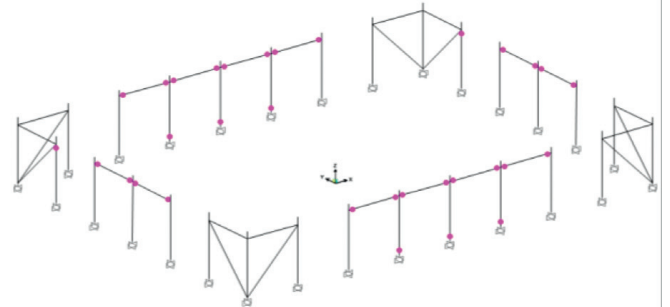

(c)

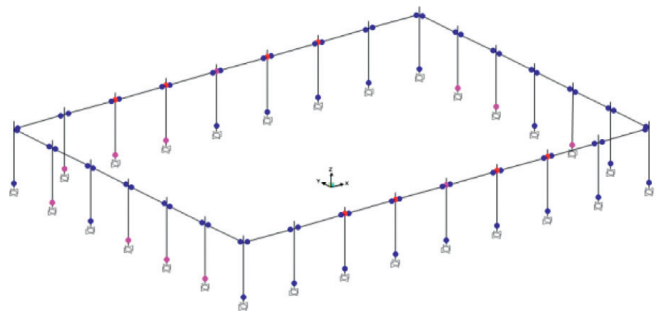

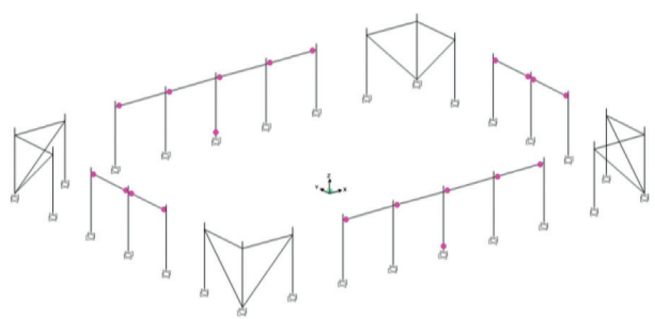

(d)

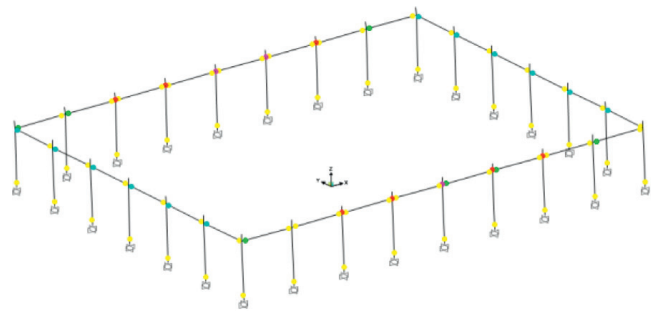

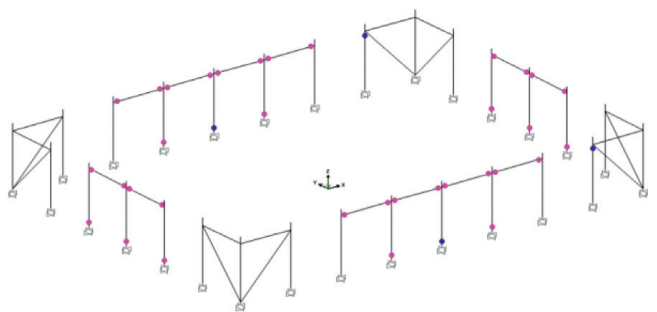

(e)

Figure 20: Plastic hinges under different earthquakes (left: SS-RC; right: SS-SRC). (a) Tohoku, (b) Mammoth Lakes, (c) Chi-Chi, (d) El Centro, and (e) Kobe.

vertical forces of roof, thus leading to the seismic responses differences including plastic hinges and lateral displacements of $\mathrm{RC}$ column tops. The most remarkable discrepancy in lateral displacements of RC column tops is in the case of Kobe's ground motion, because all the column bottoms exceed the ultimate capacities and large plastic rotations occur in the hinges of column bottoms, as is shown in Figure 20(e).
The time histories of maximum moments of $\mathrm{RC}$ column bottoms of section $600 \times 400 \mathrm{~mm}$ are depicted in Figure 21. It is apparent that the column bottom moments in SS-RC structures are significantly larger than those of SS-SRC structures, which also explains the reason for the discrepancies in plastic hinges shown in Figure 20. 


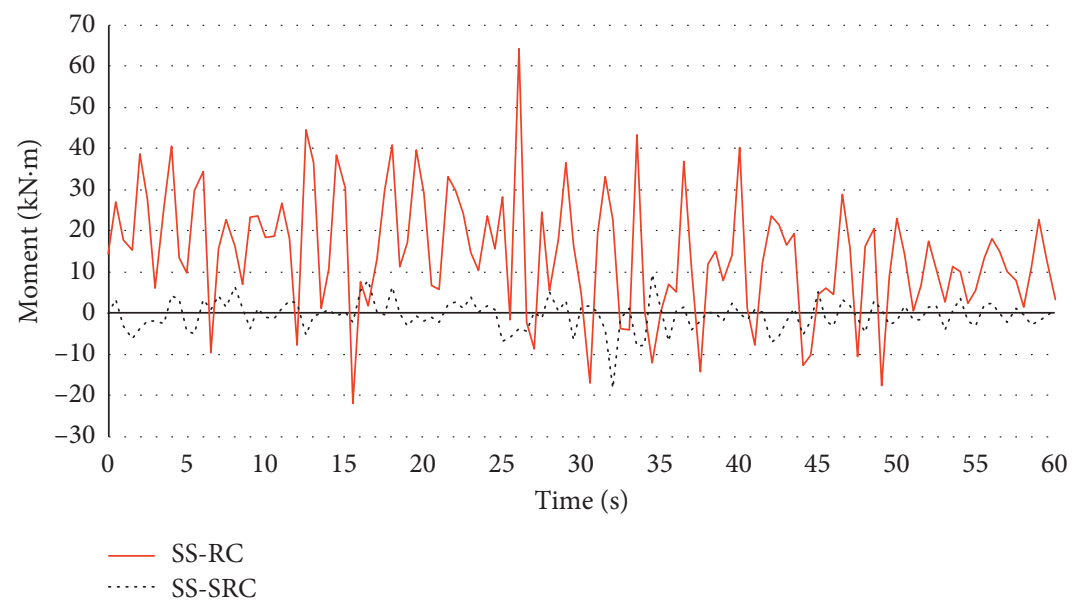

(a)

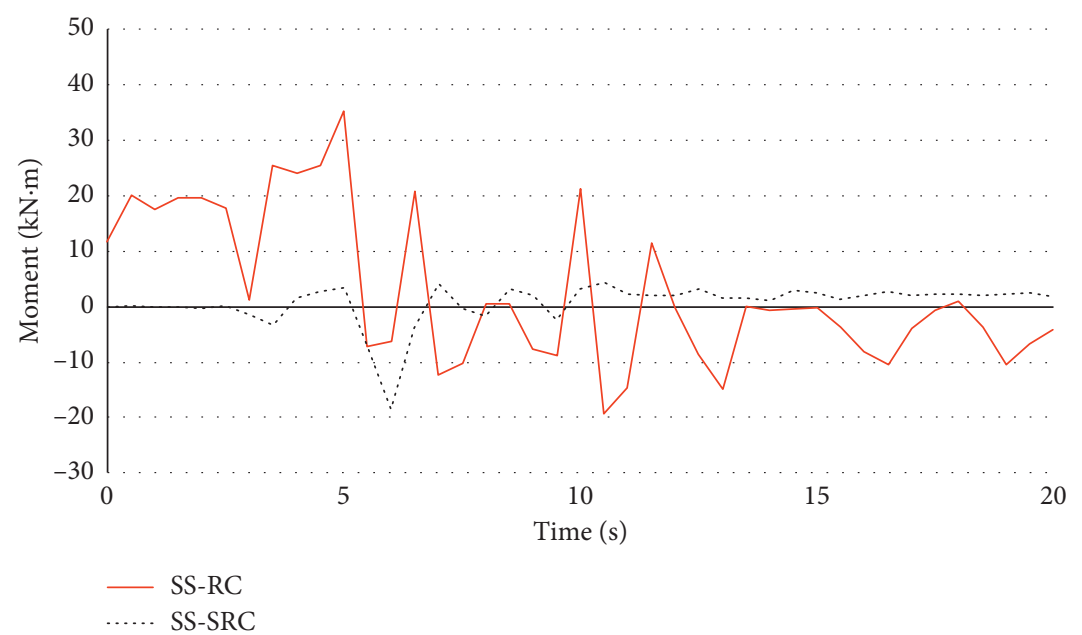

(b)

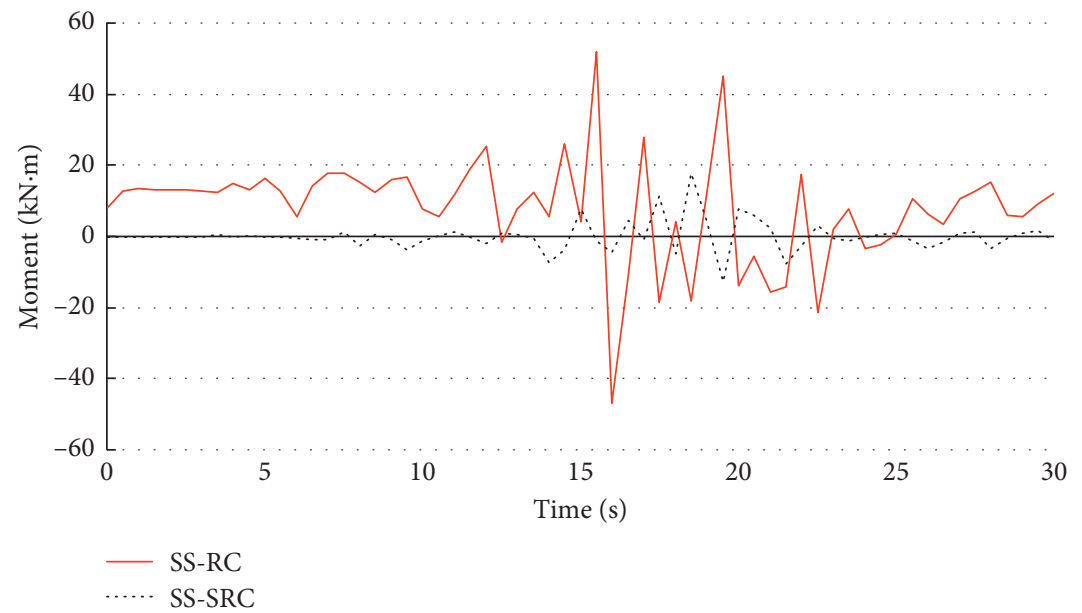

(c)

Figure 21: Continued. 


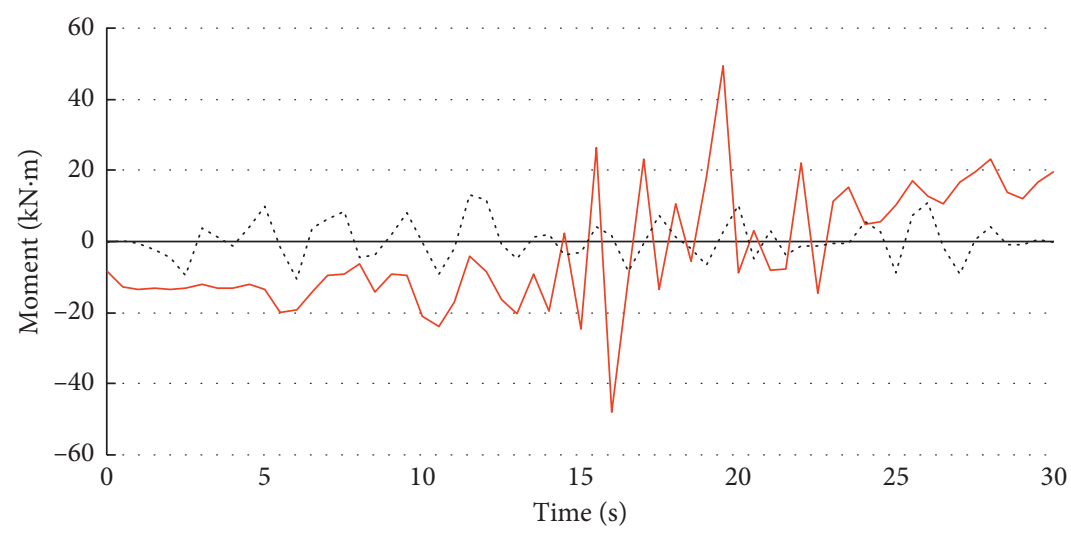

- SS-RC

…. SS-SRC

(d)

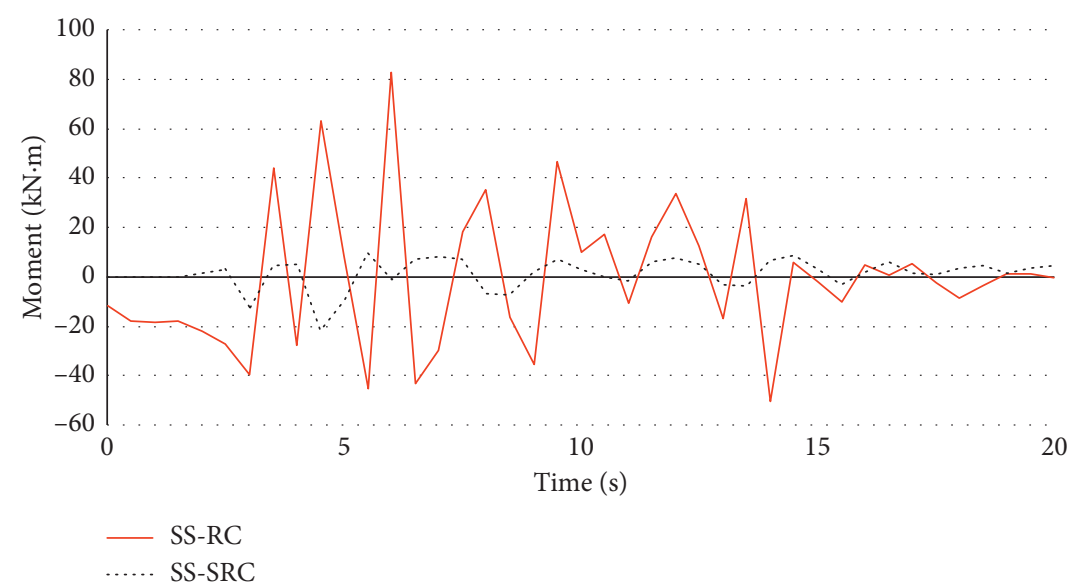

(e)

Figure 21: Time histories of maximum moments of the RC column bottoms. (a) Tohoku, (b) Mammoth Lakes. (c) Chi-Chi, (d) El Centro, and (e) Kobe.

\section{Conclusions}

Seismic damage of spatial structures of rectangular plan with $\mathrm{RC}$ substructures is observed in several earthquakes, especially in the RC substructures. In order to reduce the seismic damage potential of this kind of structure, a new structural configuration of spatial structures of rectangular plan is proposed, the substructures of which are composed of two parts: the steel substructure and the RC substructure. The former bears the horizontal and vertical forces of roof under earthquake and vertical loads, while the latter only bears the vertical load of roof by the arrangement of horizontal sliding bearings between the roof and the RC substructure. Therefore, the horizontal seismic forces of the roof can only be transferred to the steel substructure rather than the RC substructure by this kind of configuration, so the shear force and the bending moment of the RC substructure can be significantly reduced.

The static pushover analyses are performed on two kinds of simple structures with similar lateral stiffness: one is a steel braced frame with high-strength cable as braces, and the other is RC frame structures. The results show that the lateral capacity of the steel structure is much larger than those of the RC structures with different reinforcements under several vertical loads.

A spatial structure of rectangular plan with typical dimension is designed according to Chinese structural designing codes. The structure is composed of three parts: the single-layer latticed shell as roof, the boundary beam structure, and the substructures. Two kinds of substructures are considered: one is RC structure, and the other is steel structure and RC structure. Seismic time history analyses are carried out for the spatial structure with two different substructures under five ground motions. The results show that the damage mainly concentrates on the substructures, and the seismic performance of the structure with steel and RC substructures is much better than that of the structure with $\mathrm{RC}$ substructures.

\section{Data Availability}

The authors declare that all data supporting the findings of this study are available within the article. 


\section{Conflicts of Interest}

The authors declare that they no conflicts of interest in connection with the work submitted.

\section{Acknowledgments}

This work was supported by the National Natural Science Foundation of China (no. 51308326), Shandong Provincial Natural Science Foundation (no. ZR2019MEE042), and Key Laboratory of Building Structural Retrofitting and Underground Space Engineering (Shandong Jianzhu University), Ministry of Education.

\section{References}

[1] Z.-W. Yu, X.-D. Zhi, F. Fan, and C. Lu, "Effect of substructures upon failure behavior of steel reticulated domes subjected to the severe earthquake," Thin-Walled Structures, vol. 49, no. 9, pp. 1160-1170, 2011.

[2] Y. G. Li, F. Fan, and H. P. Hong, "Effect of support flexibility on seismic responses of a reticulated dome under spatially correlated and coherent excitations," Thin-Walled Structures, vol. 82, pp. 343-351, 2014.

[3] Z. Yu, S. Li, D. Lu, C. Lu, and J. Liu, "Failure mechanism of single-layer steel reticular domes with reinforced concrete substructure subjected to severe earthquakes," International Journal of Steel Structures, vol. 16, no. 4, pp. 1083-1094, 2016.

[4] K. Kawaguchi, "A report on large roof structures damaged by the great Hanshin-Awaji earthquake," International Journal of Space Structures, vol. 12, no. 3-4, pp. 137-147, 1997.

[5] T. Saka and Y. Taniguchi, "Damage to spatial structures by the 1995 hyogoken-nanbu earthquake in Japan," International Journal of Space Structures, vol. 12, no. 3-4, pp. 125-133, 1997.

[6] M. Motosaka and K. Mitsuji, "Building damage during the 2011 off the pacific coast of Tohoku earthquake," Soils and Foundations, vol. 52, no. 5, pp. 929-944, 2012.

[7] J. Dai, Z. Qu, C. Zhang, and X. Weng, "Preliminary investigation of seismic damage to two steel space structures during the 2013 Lushan earthquake," Earthquake Engineering and Engineering Vibration, vol. 12, no. 3, pp. 497-500, 2013.

[8] G. Nie, C. Zhang, J. Dai, and K. Liu, "Seismic damage investigation and seismic performance study of space doublelayered lattice structure," Journal of Performance of Constructed Facilities, vol. 32, no. 2, Article ID 04018003, 2018.

[9] Architectural Institute of Japan, "Joint editorial committee for the report on the great East Japan earthquake disaster, report on the great east japan earthquake disaster," Architectural Institute of Japan, Tokyo, Japan, 2014.

[10] D. Yang, C. Yun, J. Wu, and Y. Zhang, "Aseismic performance of large span latticed domes with separated substructures," Journal of Vibration and Shock, vol. 37, no. 3, pp. 237-242, 2018.

[11] China Architecture \& Building Press, GB 50010-2010, Code for Design of Concrete Structures, China Architecture \& Building Press, Beijing, China, 2011.

[12] China Architecture \& Building Press, GB 50011-2010, Code for Seismic Design of Buildings, China Architecture \& Building Press, Beijing, China, 2016.

[13] X. Liang, GB 50017-2003, Code for Design of Steel Structures, China Architecture \& Building Press, Beijing, China, 2003.
[14] China Architecture \& Building Press, Chinese Standard.net, JGJ 7-2010, Technical Specification for Space Frame Structures, China Architecture \& Building Press, Beijing, China, 2010.

[15] H. X. Shang, "Performance testing research of high strength steel wire products," Metal Products, vol. 39, no. 6, pp. 39-43, 2013.

[16] China Architecture \& Building Press, JGJ 257-2012, Technical Specification for Cable Structures, China Architecture \& Building Press, Beijing, China, 2012.

[17] ASCE 41-13, Seismic Evaluation and Retrofit of Existing Buildings, American Society of Civil Engineers, Reston, VA, USA, 2014.

[18] C.-H. Zhai and L.-L. Xie, "A new approach of selecting real input ground motions for seismic design: the most unfavourable real seismic design ground motions," Earthquake Engineering \& Structural Dynamics, vol. 36, no. 8, pp. 10091027, 2007. 